\title{
The Difference of Bacterial Aerosol Quantity Based on Blood Agar Plate Position
}

\author{
Novia Tri Hasanah ${ }^{1 *}$, Nila Kasuma², Aida Fitriana ${ }^{2}$ \\ ${ }^{1 .}$ Undergraduate Dental Student, Faculty of Dentistry, Universitas Andalas, Padang 25127, Indonesia \\ ${ }^{2}$ Lecturer, Faculty of Dentistry, Universitas Andalas, Padang 25127, Indonesia \\ *E-mail: noviatrihasanah@gmail.com
}

\begin{abstract}
Objective: The purpose of this study was to determine the difference of bacterial aerosol quantity based on blood agarplate position with and without using chlorhexidine as pre-procedural mouthwash in ultrasonic scaling treatment.

Methods: The 16 samples rinsed using chlorhexidine and other 16 samples rinsed using sterile water before ultrasonic scaling treatment was started. Bacterial aerosol was collected using blood agar plate for 10 minutes during ultrasonic scaling treatment and placed at three different positions: chest of patient (P-I), right side of patient-8 o'clock (P-II), left side of patient-4 o'clock (P-III).
\end{abstract}

Results: The Friedman test result showed that $\mathrm{p}=0.223$ (group I) and $\mathrm{p}<0.001$ (group II). The $\mathrm{p}=0.223$ showed that there was no significant difference of bacterial aerosol quantity based on blood agar plate position.

Conclusion: Chlorhexidine can be used on bacterial aerosol reduction during ultrasonic scaling treatment.

Keywords: bacterial aerosol, chlorhexidine, cross infection

\section{Introduction}

Indonesia is still trying to do some efforts for implementing infection control correctly. One of the facts about infection control phenomenon in Indonesia is still low reported by Listyanti. ${ }^{1}$ Listyanti 1 said that there were three dentists had been infected by HIV/AIDS in Surabaya. This case was suspected as cross infection phenomenon in health provider. Research by Kohlail2 showed that is about $17-46 \%$ dentists do not consider all patients potentially infectious, $50-86 \%$ dentists think that the medical record and patients' appearance determine the level of infection control that applied, and 18-65\% dentists think that they are right to decline treating the patients who already known the infection status. According to Lugito, ${ }^{2}$ occupational risk such as infected to infectious disease like HIV, HBV, tuberculosis, etc.; the health providers are lack of awareness; and the low quality of sterilization also causes the high prevalence of infectious disease spread. The World Health Organization (WHO) estimates that about 3 million health care workers face occupational exposure to blood borne viruses each year: 2 million to $\mathrm{HBV}, 900.000$ to $\mathrm{HCV}$, and 300.000 to HIV. The Centre for Disease Control and Prevention (CDC) reported the research result of 360 health care workers, the injured incident in dental practice: $36 \%$ dentists, $34 \%$ oral surgeons, $22 \%$ dental hygienists, and $4 \%$ dental students. Mahboobi et al. ${ }^{3}$ reported that dentists have the highest risk of being exposed to cross infection among health workers.

Cross infection is the transmission of infectious agents between patient and staff in clinical environment. This infection can transmit through instrument contamination due to improper sterilization that potentially in aerosol formation. ${ }^{4}$ Dentists use the aerosol-creating instruments such as ultrasonic scaler, high speed hand piece, polishing cups, and air-water syringe. Those instruments are used in patient's oral cavity with various microorganisms derived from saliva, blood, and dental plaque..$^{5,6,7,8,9}$ Therefore, the dentists are often exposed to microorganisms that harmful to the health. ${ }^{10}$ Mikitka et al. ${ }^{11}$ said that there is some evidence for greater prevalence of respiratory disease. This is caused by the bacterial aerosol remains in the air for long period before being inhaled by dentists or patients. ${ }^{11}$ The aerosolized bacteria can be inhaled into the lung of a susceptible person. ${ }^{12}$

Aerosol is solid or liquid particles in the air with less than $50 \mu \mathrm{m}$ in diameter. ${ }^{4,7,13,14,15}$ Aerosol is formed when the high-powered instrument requiring air pressure and water spray to work effectively. ${ }^{14,15,16}$ According to Freeman, ${ }^{15}$ the water spray act as a coolant to prevent teeth becoming damaged. The water spray itself is harmless, but when combined with the oral cavity fluid of patients can potentially cause a health risk to staff and patient. ${ }^{15}$ 
According to Pina-Vaz et al., ${ }^{17}$ ultrasonic scaler is the greatest source of aerosol contamination in dental procedures. Aerosol contains many microorganisms derived from blood, saliva, debris, dental plaque, calculus, and restorative materials produced by ultrasonic scaler when used with water spray. ${ }^{5,6,7,11,14}$ Each of the patients has different aerosol composition depends on the teeth condition in the operative area and the level of microorganisms in patients' oral cavity. ${ }^{6,13}$

The use of pre-procedural mouthwash before ultrasonic scaling treatment is one of some methods to reduce aerosol contamination. ${ }^{7,13}$ In this study, chlorhexidine as pre-procedural mouthwash was used in group I, whereas sterile water was used in group II before ultrasonic scaling treatment was started. Bacterial aerosol was collected using blood agar plate that placed at three different positions: the chest of patient, the right side of patient- 8 o'clock, and the left side of patient-4 o'clock.

Based on the description above, the research questions in this study are (1) is there any differences of bacterial aerosol quantity based on blood agar plate position between using chlorhexidine and without using chlorhexidine as pre-procedural mouthwash in ultrasonic scaling treatment, (2) is bacterial aerosol quantity using chlorhexidine less than without using chlorhexidine at each of blood agar plate positions. Thus, the research purposes of this study are (1) to determine the difference of bacterial aerosol quantity based on blood agar plate position between using chlorhexidine and without using chlorhexidine as pre-procedural mouthwash in ultrasonic scaling treatment, (2) to compare the bacterial aerosol quantity with and without using chlorhexidine at each of blood agar plate positions.

\section{Methods}

This is an experimental study in Dental Clinic of Faculty of Dentistry, Andalas University and Microbiology Laboratory that held from February to March 2016.

The sample selection criteria as follows:

\section{Inclusion Criteria}

a. Patients with moderate and severe oral hygiene indexsimplified (OHI-S) that indicated for ultrasonic scaling treatment.

b. Patients were disposed to be the research sample as stated in informed consent.

\section{Exclusion Criteria}

a. Patients with systemic disease.

b. Patients who consumed antibiotic within the last 6 months.

c. Patients who used the chemotherapy mouthwash and oral irrigation within the last 6 months. d. Patients who consumed antiseptic mouthwash within the last 6 months.

e. Patients with cardiac pacemaker.

f. Patients with respiratory infection.

g. Patients who were smoker.

h. Patients who were pregnant and lactating.

The purposive sampling technique was used for this study based on the consideration that the samples were representative on the predefined criteria. The total of 32 samples was divided into two groups (patients were 11-45 years old and no gender criteria).

Group I: The 16 samples rinsed using $10 \mathrm{ml}$ of $0.2 \%$ chlorhexidine gluconate mouthwash for 1 minute before ultrasonic scaling treatment was started.

Group II: The 16 samples rinsed using $10 \mathrm{ml}$ of sterile water for 1 minute before ultrasonic scaling treatment was started.

Bacterial aerosol was collected using blood agar plate for 10 minutes during ultrasonic scaling treatment and placed at three different positions with each of plates within 80$105 \mathrm{~cm}$ from floor:

Position I (P-I): the chest of patient $(15 \mathrm{~cm}$ from patient's oral cavity)

Position II (P-II): the right side of patient-8 o'clock (45 $\mathrm{cm}$ from patient's oral cavity)

Position III (P-III): the left side of patient-4 o'clock (40 $\mathrm{cm}$ from patient's oral cavity)

Blood agar plate was opened when operator started the ultrasonic scaling treatment. After ultrasonic scaling treatment was done (during the first 10 minutes), blood agar plate was closed and brought to the microbiology laboratory for doing the incubation process at $37{ }^{\circ} \mathrm{C}$ for 24 hours. After incubation process, the bacterial aerosol quantity was counted as colony forming unit (cfu). The data of bacterial aerosol quantity at each of groups and among groups were analyzed statistically using Friedman and Kruskal Wallis test.

The purpose of Friedman test was to identify the difference of bacterial aerosol quantity based on blood agar plate position with and without using chlorhexidine as pre-procedural mouthwash in ultrasonic scaling treatment. The purpose of Kruskal Wallis test was to compare the bacterial aerosol quantity with and without using chlorhexidine as pre-procedural mouthwash in ultrasonic scaling treatment at each of blood agar plate positions. 


\section{Results and Discussion}

The result of bacterial aerosol quantity in group I can be seen in Table 1, whereas in group II can be seen in Table 2.

Table 1. Bacterial aerosol quantity of group I

\begin{tabular}{ccccccc}
\hline & & & \multicolumn{3}{c}{ Bacterial Aerosol Quantity } \\
(cfu)
\end{tabular}

The calculation result in Table 1 above showed that in general most of the bacterial aerosol was detected on the chest of patient. The calculation result of bacterial aerosol quantity in group I showed that the highest result was at four samples $(\mathrm{C} 1, \mathrm{C} 2, \mathrm{C} 10$, and $\mathrm{C} 13)$.

Table 2. Bacterial aerosol quantity of group II

\begin{tabular}{|c|c|c|c|c|c|c|}
\hline \multirow[b]{2}{*}{ Code } & \multirow[b]{2}{*}{$\begin{array}{l}\text { Plaque } \\
\text { Score }(\%)\end{array}$} & \multirow[b]{2}{*}{$\begin{array}{l}\text { OHI-S } \\
\text { Category }\end{array}$} & \multicolumn{4}{|c|}{$\begin{array}{c}\text { Bacterial Aerosols Quantity } \\
\text { (cfu) }\end{array}$} \\
\hline & & & P-I & P-II & P-III & Total \\
\hline S1 & 40.63 & Moderate & 44 & 2 & 3 & 49 \\
\hline $\mathrm{S} 2$ & 98.21 & Severe & 124 & 8 & 9 & 141 \\
\hline S3 & 37.50 & Moderate & 300 & 6 & 6 & 312 \\
\hline S4 & 61.61 & Moderate & 176 & 2 & 2 & 180 \\
\hline S5 & 92.86 & Severe & 340 & 0 & 2 & 342 \\
\hline S6 & 87.07 & Severe & 127 & 2 & 2 & 131 \\
\hline S7 & 80.00 & Severe & 81 & 14 & 2 & 97 \\
\hline S8 & 50.00 & Moderate & 398 & 4 & 2 & 404 \\
\hline S9 & 52.70 & Moderate & 880 & 1 & 2 & 883 \\
\hline S10 & 50.00 & Severe & 161 & 2 & 3 & 166 \\
\hline S11 & 46.43 & Moderate & 18 & 2 & 2 & 22 \\
\hline S12 & 100.00 & Severe & 312 & 26 & 22 & 360 \\
\hline S13 & 100.00 & Severe & 100 & 3 & 4 & 107 \\
\hline S14 & 61.00 & Moderate & 364 & 2 & 4 & 370 \\
\hline S15 & 93.10 & Moderate & 56 & 4 & 4 & 64 \\
\hline $\mathrm{S} 16$ & 83.93 & Severe & 244 & 3 & 5 & 252 \\
\hline
\end{tabular}

The calculation result in Table 2 above also showed that in general most of the bacterial aerosol was detected on the chest of patient.

From the data in Table 1 and 2 can be described the statistical descriptive result in Table 3 for group I and Table 4 for group II.
Table 3. Statistics descriptive result of group I

\begin{tabular}{ccccc}
\hline Position & Mean & $\begin{array}{c}\text { Standard } \\
\text { Deviation }\end{array}$ & Minimum & Maximum \\
\hline P-I & 34.38 & 51.13 & 0.00 & 132.00 \\
P-II & 2.81 & 2.93 & 0.00 & 10.00 \\
P-III & 3.81 & 3.37 & 0.00 & 11.00 \\
\hline
\end{tabular}

Table 4. Statistics Descriptive Result of Group II

\begin{tabular}{ccccc}
\hline Position & Mean & $\begin{array}{c}\text { Standard } \\
\text { Deviation }\end{array}$ & Minimum & Maximum \\
\hline P-I & 232.81 & 211.49 & 18.00 & 880.00 \\
P-II & 5.06 & 6.52 & 0.00 & 26.00 \\
P-III & 4.63 & 5.02 & 2.00 & 22.00 \\
\hline
\end{tabular}

The statistics descriptive result showed that the highest mean of bacterial aerosol quantity was on the chest of patient. The bacterial aerosol quantity on the chest of patient using chlorhexidine was less than without using chlorhexidine. It was similarly with the blood agar plate on the right and left side of patient. It showed that chlorhexidine was more capable to reduce the bacterial aerosol quantity at each of blood agar plate positions.

The statistics result using Friedman test showed that $p=$ 0.223 in group I and $p<0.001$ in group II (Table 5). The $\mathrm{p}$ value of group I showed that there was statistically no significant difference, whereas the $p$ value of group II showed that there was statistically significant difference. The result of group I showed that the bacterial aerosol quantity at three different blood agar plate positions was not different which means the $0.2 \%$ chlorhexidine gluconate as pre-procedural mouthwash can reduce bacterial aerosol quantity at each of positions during ultrasonic scaling treatment. The result of group II showed that the bacterial aerosol quantity at each of blood agar plate positions cannot be affected by rinsed using sterile water so that the sterile water cannot reduce bacterial aerosol quantity at each of positions.

Table 5. The $p$ value in both group of Friedman test

\begin{tabular}{ccc}
\hline & Group I & Group II \\
\hline p value & 0.223 & $<0.001$ \\
\hline
\end{tabular}

The statistics result using Kruskal Wallis test showed that $p<0.001$ in P-I, $p=0.237$ in P-II, and $p=0.718$ in P-III (Table 6). The $p$ value of P-I showed that there was significant difference of blood agar position on the chest of patient with and without using chlorhexidine as preprocedural mouthwash in ultrasonic scaling treatment. This result showed that chlorhexidine can reduce bacterial aerosol quantity on the chest of patient which means the bacterial aerosol quantity on the chest of patient using chlorhexidine was less than without using chlorhexidine. The $p$ value of P-II and P-III showed that there was no significant difference of blood agar plate position on the right and left side of patient with and without using chlorhexidine as pre-procedural mouthwash in ultrasonic scaling treatment. In descriptively of Table 3 and 4, the bacterial aerosol on the right and left side of patient using chlorhexidine was less than using sterile water. Nonetheless, the result statistically indicated that the chlorhexidine did not show the significant difference to 
reduce the bacterial aerosol quantity on the right and left side of patient yet.

Table 6. The $p$ value at each of blood agar plate positions of Kruskal Wallis test

\begin{tabular}{rrrr}
\hline & $\boldsymbol{P}-\boldsymbol{I}$ & $\boldsymbol{P}-\boldsymbol{I I}$ & $\boldsymbol{P}-\boldsymbol{I I I}$ \\
\hline $\boldsymbol{p}$ value & $<0.001$ & 0.237 & 0.718 \\
\hline
\end{tabular}

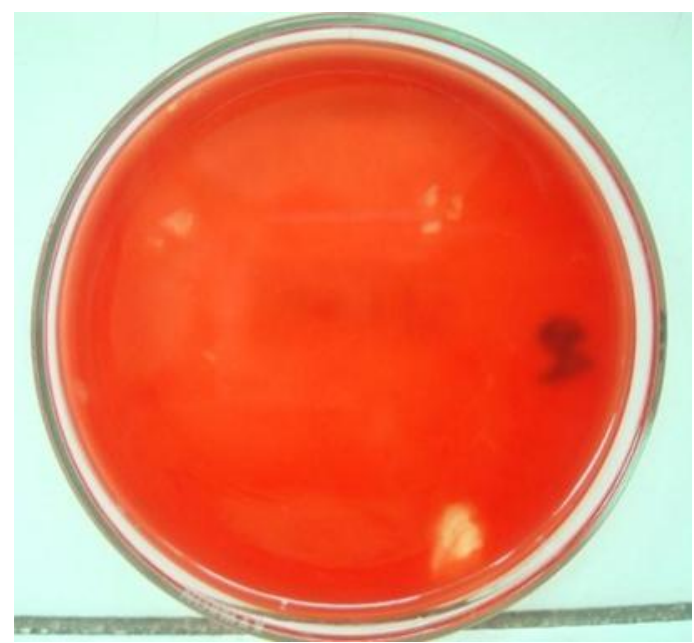

Figure 1. Blood agar plate on the chest of patient (Group I)

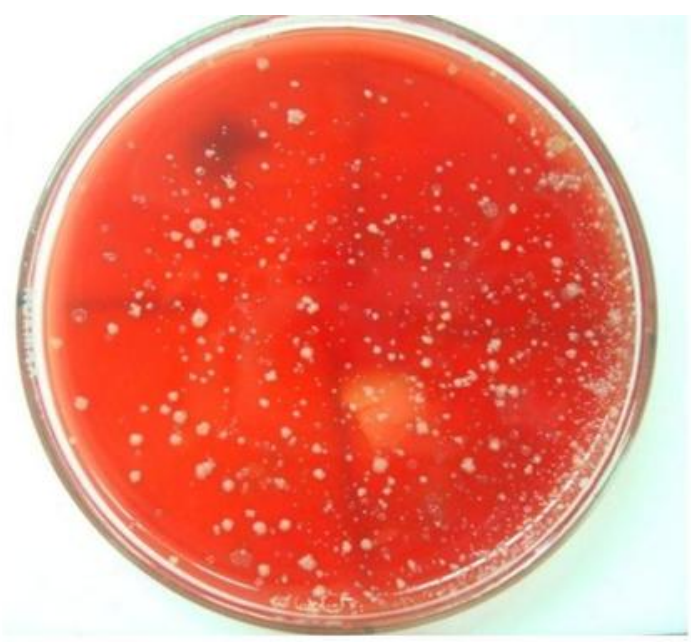

Figure 2. Blood Agar Plate on the Chest of Patient (Group II)

Aerosol is solid or liquid particles in the air with less than $50 \mu \mathrm{m}$ in diameter., $4,13,14,15$ According to Harrel and Molinari ${ }^{13}$, aerosol contamination during dental procedure consist of three main sources: (1) dental instrument, (2) saliva and respiratory source, (3) operative area. Aerosol contains microorganisms from oral cavity when highpowered and high-speed instrument is used. ${ }^{11}$ The oral cavity is a unique environment which provides an ideal medium for microbial growth. ${ }^{18}$ King et al. ${ }^{9}$ also stated that the oral cavity provides a unique ecosystem of moist environment, temperature, and the existence of endogenous and exogenous metabolic substrates, which make it an ideal medium for bacterial growth. In accordance with Kaplowitz and Collins, ${ }^{19}$ the oral cavity is host of many species: aerobic and anaerobic bacteria, virus, and fungi.

In this study, ultrasonic scaler was used in ultrasonic scaling treatment. Ultrasonic scaler is the greatest producer of aerosol contamination in dental procedures. 17 This instrument generates aerosol with bacteria which peak over $300 \mathrm{cfu} / \mathrm{cu} \mathrm{ft}$ from dental operatory.9 Meanwhile, Larato et al. ${ }^{9}$ demonstrated that during ultrasonic scaling, the bacterial count in the air increased 30-fold. Grenier ${ }^{9}$ also demonstrated dental treatment in general significant increased the level of bacteria air contamination and ultrasonic scaling produced 3 times contamination rather than operative dental treatment.

In this study, blood agar plate was used as a medium for bacterial aerosol growth. Blood agar plate is a general purpose, non-selective, enriched medium that promotes the growth of microorganisms9. In line with Legnani, ${ }^{9}$ plate method gives a precise indication of the possible contamination over time by measuring dental particulate and aerosol precipitation on different exposed surfaces in the operatory room. Blood agar plate was placed at three different positions: the chest of patient $(15 \mathrm{~cm}$ from patient's oral cavity), the right side of patient- 8 o'clock (45 cm from patient's oral cavity), and the left side of patient-4 o'clock (40 cm from patient's oral cavity). In descriptively, the result showed that the highest of bacterial aerosol quantity was on the chest of patient. This is line with a research conducted by Cochran et al. ${ }^{14}$, the number of the highest colony of aerosol is on the chest of patient because the droplet of saliva that produced during a dental procedure settle down rapidly in the air with the greatest contamination on the chest of patient.

The descriptive result showed that the mean of bacterial aerosol quantity in group I P-I (34.38) > P-III (3.81) > P-II (2.81). From this result, can be stated that the farther distance from reference point (patient's oral cavity) then the less of bacterial aerosol quantity. It is in line with a research conducted by Logothethis and Martinez ${ }^{20}$ showed that the number of cfus decrease with increasing the distance from the reference point. Nevertheless, the result of group I was not in line with group II. In group II, the mean of bacterial aerosol quantity was P-I (232.81) > P-II (5.06) > P-III (4.63). This result is maybe related to the several factors which influence aerosol distribution as stated by Bentley et $\mathrm{al}^{11}$ : type of procedure and whether high volume evacuation was used; the position of the tooth in the mouth, which affects the position of the operator relative to the subject in the dental chair; and the level of microorganisms in the subject's mouth.

The statistics calculation showed that the bacterial aerosol quantity on the chest of patient using chlorhexidine was less than without using chlorhexidine. While, it is not in line with the statistics result of blood agar plate position on the right and left side of patient. It is maybe related to the distance of blood agar plate position to reference point because of the farther distance from reference point. According to this statement, the use of chlorhexidine does 
not influence the reduction of bacterial aerosol quantity with the farther distance from the reference point. Devker et al..$^{21}$ claimed that the level of the effectiveness of $0.2 \%$ chlorhexidine in reducing cfu can be caused due to the reason that chlorhexidine starts the antimicrobial action at the point of aerosol level and at the beginning of the aerosol formation. Besides, how far the spread of aerosol and the level of contamination are still in attention. ${ }^{11}$ According to Bennet et al. ${ }^{5}$, aerosol peak decreased to the background level within 10 minutes and 30 minutes due to the rapid deposition from particles after the high level of aerosol in the patient's head (about $1 \mathrm{~m}$ from the base), particularly with scaling procedure.

Harrel and Molinari ${ }^{13}$ recommend four methods to reduce aerosol contamination: barrier protection-masks, gloves, and eye protection; pre-procedural rinse with antiseptic mouthwash such as chlorhexidine; high volume evacuator; high-efficiency particulate air room filters and ultraviolet treatment of ventilation system. In this study, chlorhexidine was used as pre-procedural mouthwash in ultrasonic scaling treatment.

Chlorhexidine is a bisbiguanid molecule that binds strongly to hydroxyapatite, organic pellicle teeth, oral mucosa, proteins in saliva, and bacteria. Because of this binding, chlorhexidine that contain in mouthwash can inhibit the high substance with $30 \%$ drug released after rinsing and remain for a long time. After rinsing with $0.2 \% 10 \mathrm{ml}$ of chlorhexidine gluconate mouthwash for 1 minute, approximately $30 \%$ of the composition of mouthwash survives. Half composition of the mouthwash will be bound with receptor molecules in 15 seconds rinsing. $^{22}$ At low concentrations, chlorhexidine is bacteriostatic resulting in increased permeability and leakage of intracellular components, including potassium. At high concentrations, chlorhexidine is bactericidal which cause the outbreak of the bacterial cell wall and cytoplasm loss that leads to cell death. As stated by Carr $^{23}$ and Cohlbecker, ${ }^{24}$ the $0.2 \%$ chlorhexidine gluconate is effective against gram-negative bacteria, gram-positive bacteria, aerobic, anaerobic bacteria, yeasts, dermatophytes, and some lipophilic viruses.

This study showed descriptively that plaque score index cannot be the benchmark to the low or high of bacterial aerosol quantity in using the $0.2 \%$ chlorhexidine gluconate mouthwash. It is in line with the statement of $\mathrm{Cobb}^{23}$, chlorhexidine is only effective on the outer layer of plaque biofilm at 24-28 hours from the formation process. Harrel and Molinari ${ }^{13}$ also stated that chlorhexidine is not effective in influencing the biofilm organism such as dental plaque.

The calculation result of bacterial aerosol quantity in group with $0.2 \%$ chlorhexidine gluconate mouthwash showed the highest score at four samples $(\mathrm{C} 1, \mathrm{C} 2, \mathrm{C} 10$, and $\mathrm{C} 13$ ). The potential sources of aerosol contamination during the dental procedure are the dental instrument, saliva and respiratory source, and operative area. The aerosol sources from dental instrument are produced by microorganisms in the instrument and dental unit water line. ${ }^{13}$ The use of water flow at the tip of ultrasonic scaler cannot be controlled when the operator used the instrument so that the amount of water flow is different at every patient. Reducing the water flow decreases the amount of aerosol released into the air. ${ }^{23}$ The aerosol sources from the patient are saliva, secretion from the nose and throat, dental plaque, gingival secretion, dental tissue, and the materials that used in the dental treatment. ${ }^{6}$ It can cause every patient has different aerosol composition depends on the teeth condition in the operative area and level of microorganisms in patient's oral cavity so that the OHI-S cannot be the benchmark to the high or low level of bacterial aerosol quantity that incurred during ultrasonic scaling treatment. ${ }^{6,13,18}$

Research that supports this study is a research conducted by Acharya et al. ${ }^{14}$ about the amount of aerosol contamination produced by ultrasonic scaler and high speed air turbine hand piece in the immediate vicinity of the patient's mouth during dental procedures in a rural dental clinic and the level and the type of microbial contamination present on the white coasts of dental personnel in a rural dental setting. The results showed the highest number of colonies was from patient's chest area and least cfu/plate was at a distance of 24 inches away from the operating area during both procedures. Significantly higher colony count was seen during oral prophylaxis (ultrasonic scaling treatment) than during cavity preparation.

Other research that supports this study was done by Sawhney et al. ${ }^{11}$ regarding the efficacy of two commercially available mouth rinses $(0.2 \%$ chlorhexidine and Listerine) in reducing bacterial contamination when used a pre-procedural rinse, with and without high volume evacuation. The results showed that $0.2 \%$ chlorhexidine was the best in reducing aerobic bacteria followed by Listerine and then water. The use of $0.2 \%$ chlorhexidine and high volume evacuator is the best in reducing aerosol contamination during ultrasonic scaling.

Shetty et al. ${ }^{20}$ about the efficacy of pre-procedural mouth rinses (chlorhexidine gluconate and tea tree oil) in reducing microbial content of aerosol product during ultrasonic scaling procedures by viable bacterial count. The results showed that all the antiseptic mouthwash significantly reduced the bacterial cfus. Chlorhexidine rinses were found to be superior to tea tree oil when used pre-procedurally in reducing aerosolized bacteria.

Based on these findings, the research author has suggestions: the use of high-efficiency particulate air room filter is recommended to maximize in reducing aerosol contamination during dental procedures, and add the amount of blood agar plates at other different positions in order to obtain more varied results.

\section{Conclusions}

From the research findings can be concluded: (1) the bacterial aerosol quantity at each of blood agar plate positions using chlorhexidine is not different which means chlorhexidine as pre-procedural mouthwash can reduce 
bacterial aerosol quantity during ultrasonic scaling treatment at each of blood agar plate positions; the bacterial aerosol quantity at each of blood agar plate positions cannot be influenced by using sterile water so that the sterile water cannot reduce the bacterial aerosol quantity at each of blood agar plate positions, (2) the bacterial aerosol quantity using chlorhexidine is less than without using chlorhexidine of blood agar plate on the chest of patient; there is significant difference of bacterial aerosol quantity with and without using chlorhexidine on the chest of patient; there is no significant difference of bacterial aerosol quantity with and without using chlorhexidine on the right and left side of patient.

The $0.2 \%$ chlorhexidine gluconate as pre-procedural mouthwash can be used on bacterial aerosol reduction during ultrasonic scaling treatment. The $0.2 \%$ chlorhexidine gluconate can be recommended as an antibacterial in preventing cross infection.

\section{References}

1. Listyanti, AS. [Online] 3 Dokter Gigi Tertular Pasien Pengidap AIDS. Tempo, 5 March 2013. Available from https://m.tempo.co/read/news/2013/03/05/173465 143/3dokter-gigi-tertular-pasien-pengidap-aids. [Accessed on 5 July 2016]

2. Lugito, Manuel. Kontrol Infeksi dan Keselamatan Kerja dalam Praktek Kedokteran Gigi. Jurnal PDGI. 2013; 62(1), p. 24.

3. Jawdekar, AM. Infection Control Policy for Dental Practice: An Evidence Based-Approach. Journal of Contemporary Dentistry. 2013; 3(2), p.82.

4. Samaranayake, Lakshman. Essential Microbiology for Dentistry. (4th ed.). United Kingdom: Elsevier; 2012. p. 325-327.

5. Bennett AM, Fulford MR. Microbial Aerosols in General Dental Practice. BritishDental Journal. 2000; 189(12), p. 1

6. Szymańska, Jolanta. Dental Bioaerosol as an Occupational Hazard in a Dentist's Workplace. Ann Agric Environ Med. 2007; 14 p. 204.

7. Miller CH, Palenik CJ. Infection Control and Management of Hazardous Materials for the Dental Team. ( $3^{\text {rd }}$ ed.). UK: Elsevier; 2010.

8. Brookman, Linda. Control the Aerosol Risk. The Journal of Professional ExcellenceDimensions of Dental Hygiene; 2013.

9. Kaur R, Singh I. Aerosols a Menace for the Dental Healthcares. Journal ofPharmaceutical and Biomedical Sciences; 2013 p. 58.

10. Szymańska, Jolanta. Microbiological Risk Factrors in Dentistry Current Status of Knowledge. Ann Agric Environ Med; 2005 p. 157.

11. Sawhney A, Venugopal S, Babu GRJ, et al. (2015). Aerosols How Dangerous They Are in Clinical Practice. Journal of Clinical andDiagnostic Research, 9(4), pp. 52-56.

12. John, Michael. Risk of Bacterial Transmission in Dental Practice. J Can DentAssoc. 2000; 66(10).

13. Harrel SK, Molinari J. Aerosols and Splatter in Dentistry A Brief Review of The Literature and Infection Control Implications. Journal of American Dental Association. 2004; 135 p. 429-436.

14. Acharya S, Priya H. Aerosol Contamination in A Rural University Dental Clinic in South India. Int J Infect Control. 2010; 6(1): 1-5.

15. Freeman, Julia. Risk of Aerosol Contamination around the Dental Chair. DentalNursing Journal. 2013; 9(1):1.

16. Monteiro PM, Carvalho A. Air Quality Assessment during Dental Practice: Aerosols Bacterial Counts in a University Clinic. RevistaPortuguesa de Estomatologia, Medicina Dentaria Cirurgia Maxilofacial Elsevier. 2013; 54(1): 3
17. Pina-Vaz I, Pina-Vaz C. Evaluating Spatter and Aerosol Contamination during Opening of Access Cavities in Endodontics. RevClin Pesq Odontol. 2008; 4(2): 78-82.

18. Shivanaikar S, Patil S. Aerosol during Ultrasonic ScalingAn Occupational Hazard. Guident; 2014 p. 57.

19. Kaplowitz GJ, Collins FM. Pre-Procedural Rinsing: A PreEmptive Protocol. Dental Economics; 2007.

20. Shetty SK, Sharath K. Compare the Efficacy of Two Commercially Available Mouthrinses in Reducing Viable Bacterial Count in Dental Aerosol Produced during Ultrasonic Scaling when used as a Pre-procedural Rinse. TheJournal of Contemporary Dental Practice. 2013; 14(5):851.

21. Devker N, Mohitay J, Vibhute A, et al. A Study to Evaluate and Compare the Efficacy of Preprocedural Mouthrinsing and High Volume Evacuator Attachment Alone and in Combination in Reducing the Amount of Viable Aerosols Produced during Ultrasonic Scaling Procedure. The Journal of Contemporary Dental Practice. 2012;13(5):687.

22. Heasman, Peter. Restorative Dentistry, Paediatric Dentistry, and Orthodontics. (3rd ed). UK: Elsevier; 2003.

23. Hinchman SLS. Ultrasonic Instrumentation Instruction in Dental Hygiene Programs. Master of Science in Dental HygieneThesis; 2011 p.17.

24. Reddy S, Prasad MGS. Efficacy of $0.2 \%$ Tempered Chlorhexidine as a Pre-Producedural Mouth Rinse: A Clinical Study. Journal of Indian Society of Periodontology. 2012; 9(1): 215. 